\title{
Integrated Assessments Of River Health Using Decision Support Software
}

\author{
W. J. Young ${ }^{1}$, W. G. Booty ${ }^{2}$, P. A. Whigham ${ }^{1}$ and D.C. L. Lam ${ }^{2}$ \\ ${ }^{I}$ CSIRO Land and Water, GPO Box 1666, ACT 2601 Australia, \\ ${ }^{2}$ NWRI, Environment Canada, Ontario, Canada
}

Key words: Decision Support, River Health

\begin{abstract}
A prototype decision support system has been developed to assess the environmental outcomes of proposed flow regimes for the regulated, lowland floodplain rivers of the Murray-Darling Basin in Australia. The DSS assesses the environmental outcomes of proposed flow regimes primarily by providing integrated assessments of river health at different spatial scales based on the outputs from riverine habitat condition and riverine nuisance species models. These models rely on data from river hydrology simulation models - both within and external to the DSS. The current version of the software includes three models of riverine habitat condition: native fish, floodplain vegetation, and waterbird breeding. The only riverine nuisance species model currently included is a model to predict the severity of blue-green algal blooms. In this paper a brief description of the DSS framework and the nature of the underlying models is provided. The paper focuses on describing the methods used to integrate the individual model outputs into overall river health assessments.
\end{abstract}

\section{INTRODUCTION}

The Murray-Darling Basin covers 1 million $\mathrm{km}^{2}$ - one seventh of the area of Australia. The basin is mainly devoted to extensive agriculture, including large areas of irrigation. As rainfall in the basin is highly variable and on average very low, the rivers of the basin have been impounded to provide a more reliable water supply. The basin contains a mosaic of riverine habitats - including extensive floodplains and associated wetlands and these habitats support a rich array of flora and fauna. Extensive 
anthropogenic changes have led to widespread changes in the riverine environment, including loss of habitat, loss of upstream-downstream and river-floodplain connectivity, and reductions in biodiversity. River regulation and diversions are important drivers of ecological change in many rivers of the basin. Water storage capacity and the extent of irrigated agriculture increased unchecked until 1995 when a basin-wide audit revealed that $80 \%$ of the mean annual flow for the entire basin was being diverted for consumptive use (MDBMC, 1995). In addition, the existing flow regulation system would allow higher levels of diversion if no intervention was taken. As a result, a 'cap' on further diversions was agreed to, and this cap has been in place since that time. State governments are in the process of working with the community to determine environmental flow requirements for the rivers of the basin. In this process environmental flows have been loosely defined as the flow regime required to protect the ecological integrity of river systems. While the details of the process adopted varies between states, the underlying principles are similar, and all determinations seek to use the best currently available scientific information. For the regulated rivers of the basin, this generally involves the use of river hydrology simulation models. The simulation models provide detailed information on river flow regimes under different management scenarios, and in some cases also provide estimates of likely economic outcomes of these scenarios. The models do not however, provide explicit assessments of the environmental outcomes of these scenarios.

\section{DESCRIPTION OF THE DSS}

Our prototype DSS uses the hydrological predictions of river simulation models to drive models of environmental response. The DSS has been designed specifically for use in community workshop situations - that is, for a non-technical user group. The DSS was developed in a case study context in the Border Rivers catchment of New South Wales and Queensland in Australia including frequent consultation with non-technical community representatives to ensure suitability to the user group (Cuddy et al., 1999). The DSS uses imported data from river hydrology models to drive a simple water balance model of the riverine floodplain (Whigham et al., 1997). The river and floodplain hydrology data are used as inputs to a range of models and data analysis tools to allow investigation of the likely environmental outcomes of different flow scenarios. The models include a qualitative model of river channel change based on the relationships of Schumm (1977), and riverine habitat condition and riverine nuisance species models (Young et al. 1999). The analysis tools include statistical analysis of river and 
floodplain hydrology data as described by Young (1998). The outputs from all these analyses can presented in a range of graphical and tabular forms.

The DSS has been developed using tools from the RAISON ${ }^{\mathrm{TM}}$ environmental software package (Lam et al., 1994) with substantial additional code written using Microsoft Visual Basic ${ }^{\mathrm{TM}}$ V3.0. The DSS uses Microsoft Access ${ }^{\mathrm{TM}}$ databases and runs on standard IBM compatible PC machines under Microsoft Windows ${ }^{\mathrm{TM}}$ (NT or 95). Stand-alone help and information modules are provided using hyper-text mark-up language developed using NetObjects ${ }^{\mathrm{TM}}$. The system requires a licensed copy of RAISON $^{\mathrm{TM}}$ to operate. The system architecture is described in Young et al. (1997) and Davis and Young (1998).

\section{HABITAT CONDITION ASSESSMENTS}

The integrated river health assessments the DSS provides are based on the outputs of models of riverine habitat condition and riverine nuisance species. The riverine habitat condition models provide an assessment of the positive environment values of the system, while the riverine nuisance species models, provide an assessment of the negative environmental values of the system. The integration assessments are determined as a summation of the positive environmental values minus the negative environmental values. The prototype DSS includes three riverine habitat condition models: native fish, floodplain vegetation and waterbird breeding. These models were developed especially for the prototype DSS, based largely on information acquired through interviews with expert ecologists. Data does not exist at present to validate these models. The models only represent the water regime related aspects of habitat condition for particular biota groups. They do not consider the actual responses of the biota to habitat condition. The habitat condition models combine representations of habitat preferences for different biota groups into dimensionless index values representing habitat condition. The habitat preferences for hydrologic variables such as flood timing, flood duration and flood frequency which the models use, are analogous to the preference curves for hydraulic habitat variables used in the instream flow incremental methodology (Bovee, 1982). The model outputs depend entirely on the definition of the habitat variable preference curves. While some default curves are provided in the DSS for some species or species groups, it is expected that technical users, assisted by expert ecologists, will specify these preference curves for each application of the DSS. A full description of the habitat condition models and their scientific basis is provided in Young et al. (1999).

One riverine nuisance species model is included - a model to predict the populations of blue-green algae occurring in weir pools. While blue-green 
algae are native to the system, under the changed environmental conditions now common in many rivers in the Murray-Darling Basin, algal populations are often extremely high, causing a range of negative environmental and human impacts, including high concentrations of algal toxins. The algal model is based on a simple exponential population growth and decay model, with growth only occurring when the weir pool is thermally stratified. The determination of stratification is based on an energy balance including consideration of radiation, humidity, evaporation, wind speed, and river flow rate. The model is based on the experimental work of Webster et al. (1996) and the subsequent modelling work of Bormans and Webster (1997).

\section{LOCALITIES AND ZONES}

The DSS recognises 'localities' and 'zones', and these provide the basis for the spatial integration of model outputs. The models in the DSS are run at single 'localities'. The system recognises five locality types: river sections, weir pools, floodplains, billabongs, and wetlands. The models are aspatial, and so while localities have a real world extent - for example, a $50 \mathrm{~km}$ long river section - they may be conceptualised as points. Each simulation model may only run at specified locality types, and only at specified localities of that type (or types). A database table defines the valid model type-locality type associations for an application. A table in the database associated with each separate model defines the valid localities for that model.

The system also recognises river 'zones'. For most of the major rivers of the basin a sequence of four zones can be identified: (i) upland river zone, (ii) lowland river zone, with a confined floodplain - on the slopes, (iii) lowland river zone, with a confined floodplain - on the plains, and (iv) lowland river zone, with an open, or unconfined floodplain - on the plains. River zones are defined on the basis of the large-scale geomorphology and hydrology of the river system. However, typically, flow regulation and diversion begins at the end of the upland zone, which is often not represented in the hydrology simulation model. In this case, the DSS will only consider the lower three of the four zones.

Each locality within an application must fall in a single zone only. Even large localities - such as long river sections, or expansive floodplains cannot cross a zone boundary. Localities should therefore be determined after zones are defined. As explained in more detail below: zone condition is a function of the conditions at the localities within the zone; similarly, the overall catchment condition is a function of the condition of each of the zones. 


\section{MULTI-LOCALITY ASSESSMENTS}

Because the module for integrated assessments integrates across multiple localities, it is known as the Multi-locality Integrated Assessment - or MIA - module. The MIA integrates in three ways. Firstly, it integrates across assessment 'groups'. Each of the habitat condition and nuisance models for a locality may be run separately for a number of different species, or species 'groups'. For example, the waterbird breeding habitat condition model includes two groups: Ducks and Ibis. For each time step, the MIA integrates these separate group values into a single value for waterbird breeding habitat. Secondly, the MIA integrates across time. The time series output for each individual assessment module are integrated into a single value for a scenario. Thirdly, the MIA integrates across space. The assessments from multiple localities can be integrated into a single value for a zone, for a group of zones, or for the entire catchment.

In the extreme then, the MIA module can integrate the time series outputs from all nuisance and habitat condition modules at all localities into a single value for the entire catchment. This provides a single river health score for the catchment for a scenario. Direct comparisons between scenarios can be based on this score, and the incremental changes in river health can be compared to the incremental changes in flow regime. The MIA provides a simple and overall assessment of river health, but in simplifying and integrating, much detailed information is lost. For example, the MIA obscures the variability in river health through time - what is the sequence of highs and lows; the MIA can also obscure the variability of river health across the catchment - where do the best and worst conditions occur. Depending on the questions to be answered, the MIA may or may not be the most appropriate tool in the DSS to use. It is simple and quick to use, but sacrifices much of the detail of the available information.

The calculations performed for the MIA are described sequentially in the sections below. Firstly, the integration across groups is performed, followed by the integration across time. Then, integrations across space - localities and zones - are possible. The MIA module specifically excludes integrations across assessment modules at a single locality. This is because the MIA does not attempt to give an integrated assessment of river health for a single locality - rather it is designed to integrate across localities.

Group integration, calculates a single time series of annual index values for the assessment module, using the separate time series for each group. The MIA module allows for each group to be weighted differently, to reflect the different relative importance of each group to the overall condition. The weights are important, as for example, in the fish habitat condition module, one of the groups contains only one fish species, while another, contains up 
to seven species. Certain fish species may be more abundant, or may be very rare and hence of high conservation values. There are many different and valid ways to assign weights to groups - this is a user decision, and may reflect community values and/or advice from expert ecologists. Equation 1 shows how each value in a group-integrated time series is calculated.

$$
\text { Group Integrated Value }=\sum_{g=1}^{G} f_{g} \text { Group Index }_{g} \quad \text { (Equation 1) }
$$

where $t=$ time, $G=$ number of groups, $g=$ group number, $f$ are normalised group weights, and the Group Index is the index value for a single time step, for a single group, for a given scenario, at a given locality.

Once the group integration has been performed, the values in these times series are integrated to give a single value for each model-locality-scenario combination. The values in the time series are simply averaged to give an integrated value (Equation 2). That is, each value in the time series is weighted equally.

$$
\text { Time Integrated Value }=\frac{1}{N} \times \sum_{n=1}^{N} \text { Index }_{n} \quad \text { (Equation 2) }
$$

where $N=$ the number of time steps, and $n=$ the time step number. The index value for each time step is that group integrated value calculated by Equation 1. Comparisons of the values calculated by Equation 2 can be made either at a locality between different scenarios - that is, how does the environmental conditions change with flow conditions for one model at one locality; or for a scenario between localities - that is, how do environmental conditions vary through the river system for a given flow scenario.

The spatial integration provided in the MIA is firstly, the integration of locality results to zone results, and secondly, the integration of zone results to a whole of catchment result. Spatial comparisons between localities are also possible, as described under Temporal Integration above, but these comparisons do not require spatial integration of results.

Zonal integration combines the results from Equation 2 for all localities within a zone. There are two allowable zonal integrations. Firstly, the results for a single assessment type - for example, the fish habitat condition assessment - can be integrated for a zone; or secondly, the results for all nuisance and habitat condition assessments can be integrated for a zone. The first integration assesses the conditions for a single component across a whole zone, the second, assesses overall river health for a zone. Integration of more than one assessment type, but less than all, are not allowed. Such integrations are not considered meaningful.

Two sets of weights are used in the zonal integrations. Firstly, for an assessment type, different weights can be placed on each locality in the zone. 
For example, in a given zone there may be several river sections at which the fish habitat condition assessment is run. The results from each river section in the zone may be weighted differently. Locality weights for each model are user-defined. As the assessment modules only determine the condition or quality of habitat at a locality, locality weights can be used to represent the amount of habitat provided by a locality. One sensible approach to setting locality weights then is on total length - for river sections, or total area - for floodplain localities. However, where flow conditions vary greatly between river sections of similar length, or storage volumes vary greatly between wetlands of similar area, estimation of weights on the habitat volume in each locality should be attempted. The zonal integration for a single assessment type is calculated as shown in Equation 3.

$$
\text { Zone Integrated Value for One Model }=\sum_{l=1}^{L} u_{l} \text { Index }{ }_{l} \text { (Equation 3) }
$$

where $l=$ locality, $L=$ number of localities in the zone, $u=$ normalised locality weight, and the index value is the group and time integrated value for the locality as calculated by Equation 2 .

The second type of weights used in zonal assessments are assessment type - or model - weights. These are used when all the results for all models applicable in a zone are integrated into a single result. These weights allow the relative importance of each model to the overall river health of the zone to be represented. When zonal integration for all models is performed, first, the overall result for each individual model for the whole zone is calculated using Equation 3, and then, the model weights are applied as shown in Equation 4 to calculate an overall result.

$$
\text { Zone Integrated Value for All Models }=\sum_{m=1}^{M} v_{m} \text { Index }_{m} \quad \text { (Equation 4) }
$$

where $m=$ model, $M=$ number of models applicable to the zone, $v$ =normalised model weight, and the index value is the group, time and locality integrated value for a single model as calculated by Equation 3 .

The results for individual zones - either for a single assessment type, or for all assessment types - can be integrated into a single value for the whole catchment, or for a number of spatially contiguous zones. That is, a single value for two or three contiguous zones can be determined. Once again, zone weights can be used in the calculation of the result, to reflect the relative importance of each zone to the overall result. Typically, this would reflect either the relative lengths of river in each zone, or the relative areas of floodplain in each zone. The weights thus allow more importance to be 
placed on the conditions in the larger river zones. The calculation of contiguous zone and catchment values is shown in Equation 5.

$$
\text { Multiple Zone Value }=\sum_{z=1}^{Z} w_{z} \text { Index }_{z} \quad \text { Equation } 5
$$

where $z=$ zone, $Z=$ number of zones being integrated, $w=$ normalised zone weights, and the index values is the group, time, and locality integrated value either for one model from Equation 3, or for all models from Equation 4.

\section{APPLICATION OF DSS}

While the prototype DSS has been developed using data from the Border Rivers catchment in New South Wales and Queensland, the DSS was developed as a generic system for application in any of the many river systems in the Murray-Darling Basin. As the system is a prototype, it has not been used in a decision making process to-date. Application of the DSS to decision making in the Border Rivers catchment is not politically appropriate at this stage. Nevertheless, the DSS has been developed with significant community input, and feedback from the community group and from participants of a recent training workshop indicate a range of potential users believe the DSS would be a useful tool to community groups and to water management agencies. Clearly, the usefulness of the DSS depends not only on the ease of use, but on the reliability of the models it uses to assess environmental outcomes. The ecological understanding of Australian inland rivers is very limited and so the current ability to provide models which adequately capture the response to changing flow is also limited. The current habitat condition models in the DSS are largely based on expert opinion, which is nonetheless 'best available science' for these rivers at present. An important precursor to their use however, is their review and validation by the experts who provided the knowledge upon which they are based. This will occur in the near future as a part of an independent review of the project, the DSS and its models, and the potential market for the software. Following the review, further development and refinement of the DSS, and further development of the models is likely to occur.

\section{SUMMARY}

A DSS has been developed that allows non-technical users to investigate the hydrology of environmental flow regimes, to simulate the likely future conditions of key aspects of the riverine environment, and to integrate these 
simulation results across time and space. These integrated assessments of river health allow simple comparisons between proposed flow scenarios, and assist in the necessary trade-off between environmental and consumptive uses of water. As the DSS is a prototype at this stage, application of the DSS in a real world decision making process has not yet occurred, and so the usefulness of the tool cannot be fully assessed.

\section{ACKNOWLEDGMENTS}

The authors thank the Murray-Darling Basin Commission, the Land and Water Resources Research and development Corporation, and Environment Australia for financial support of this project. Project staff from NWRI and CSIRO are thanked for their technical and intellectual contributions, especially Susan Cuddy, Trevor Farley, Ken Brown, Frances Marston, Alex Story and Phillip Fong.

\section{REFERENCES}

Bormans, M. and Webster, I.T. (1997) A mixing criterion for turbid rivers. Environmental Modelling and Software, 12(4), 329-333.

Bovee, K.D. (1982) A guide to stream habitat analysis using the instream flow incremental methodology. Instream Flow Information Paper No.12. Washington, DC: U.S. Fish and Wildlife Service (FWS/OBS-78/3).

Cuddy, S.M., et al. (1999) Which button and bars?, this publication

Davis, J.R. and Young, W.J. (1998) A Decision Support System for planning environmental flows. In: Loucks, D.P. (ed.) Restoration of Degraded River Systems: Challenges, Issues and Experiences, 357-376. Kluwer Academic Publishers, Netherlands.

Lam, D., Mayfield, C., Swayne, D. and Hopkins, K. (1994) A prototype information system for watershed management and planning. Journal of Biological Systems, 2(4), 499-517.

MDBMC (1995) An Audit of Water Use in the Murray-Darling Basin. Murray-Darling Basin Ministerial Council, Canberra, ACT, Australia.

Schumm, S.A. (1977) The fluvial system. John Wiley and Sons, New York.

Webster, I.T., Jones, G.J., Oliver, R.L., Bormans, M. and Sherman, B.S. (1996) Control strategies for cyanobacterial blooms in weir pools. Murray-Darling Basin Commission, NRMS Project M3116 Final Report, 72pp.

Whigham, P.A., Young, W.J. and Scott, A.C. (1997) Modelling River and Floodplain Interactions for Ecological Response, MODSIM 97, Proceedings of International Congress on Modelling and Simulation, Vol 1, pp 417-421.

Young, WJ., Lam, D.C. Ressel, V. and Wong, I.W. (1997) Development of an Environmental Flows Decision Support System. In: Denzer, R., Swayne, D. and Schimak, G. (Eds). Environmental Software Systems, Vol 2, pp87-94, Chapman \& Hall, London.

Young, W.J. (1998) Hydrologic descriptions of semi-arid rivers: an ecological perspective. In: Kingsford, R.T. (Ed). "Free-flowing river: the ecology of the Paroo River". Proceedings of the Paroo Scientific Workshop, 1997. NSW National Parks \& Wildlife Service.

Young, W.J., Cuddy, S.M., Marston, F.M. and Farley, T.F.N. (1999) Environmental Flows Decision Support System - a prototype. CSIRO Land and Water Technical Report 11/99. 